In these terms, rapid demonstration that AIDS is indeed caused by a virus is a triumph, even if not quite the "triumph over disease" that Mrs Margaret Heckler, the US Secretary of Health, described it last week. The triumph is that the research community has been able to respond so quickly to an unexpected development such as the emergence of AIDS. The explanation is again simple, exasperatingly so - the richness and diversity of the biomedical research enterprise, in the United States in particular but also throughout the world.

More good luck? Almost certainly not. The chances are high that in the present pattern of medical research, there would have emerged some group of workers somewhere in the world able and willing - to turn from its long-term interests to throw light on a medical emergency such as that which cropped up three years ago. This is exactly what happened a decade ago with Legionnaires' disease, in its time also a threat to people's peace of mind. None of this diminishes the importance of what Montagnier and Gallo have separately done although, with both Legionnaires' disease and AIDS, the work done by the Centers for Disease Control at Atlanta, Georgia, deserves widely to be applauded. (So too does that of the clinicians who, in the past three years, have been required to treat AIDS patients with forms of therapy offering palliation only, who have in the process courageously taken to unprecedented lengths the openness and compassion that ideally characterize relationships between physicians and their patients and whose services in this regard will unhappily be required for many years to come.)

The moral, for Mrs Heckler as well as for the impatient sections of advanced communities eager to indulge the luxury of pretending that the practice and the pursuit of medicine have long since been replaceable by suitable doses of orange juice, physical exercise and mental application, is that the deliberate provision of medical care is in one important sense only a little more certain now than, say, a century ago. By means of large and costly social expenditures in research laboratories and clinics, the incidence of avoidable death is kept at a socially acceptable low level, but there is no avoiding the hazards still unknown. The best that can be done is to be prepared to deal with these hazards quickly, as they declare themselves. The case of AIDS has triumphantly illustrated the versatility of the biomedical research system patiently put in place in recent decades. Successive US governments have been especially farsighted in recognizing the importance of such a development. It is to be hoped that this latest emergency will help to win wider acceptance of the value of a vigorous research enterprise. For there is no prospect of a triumph over disease in general.

\section{Double-talk on animals}

\section{NIH seems more ready to risk its reputation}

\section{than to meet serious critics on animal care.}

ANTIVIVISECTINASTS and other crusaders have never made intellectual integrity one of their top priorities. Appeals to emotion, however inconsistent or however specious, continue to be the hallmark of those who wish to halt animal experiments. So it is no accident that cute animals - preferably those with a lot of fur - star in the antivivisectionists' advertising campaigns (which have now reached the underground railway system in Washington, DC, in the form of posters of a child with a dog and a message that scientists who have perfectly reasonable alternatives to animal experimentation are hoping to make that dog suffer).

The National Institutes of Health (NIH), which support the majority of animal experiments in the United States, have now apparently decided that they too can play that game. At the first of what will be a series of meetings around the country, NIH produced for the public's heartstrings real-life patients and their families who have benefited from animal experiments. While the sincerity of what these patients had to say is indisputable, one has to feel uncomfortable at the exploitation of their misfortune inevitably at play when the federal government stands them up to say how much they love their husbands and how grateful they are that medical research has kept their children's daddies alive.

One has to feel even more uncomfortable at the nagging suspicion that NIH's simultaneous announcement of a new and supposedly tougher set of rules for the care and use of laboratory animals is nothing more than a part of this same public relations campaign. This conclusion can only be reinforced by NIH's simultaneous release of a study of animal experimentation at ten research institutions, chosen at random, that finds the old rules are working fine and that there are no problems to correct. If so, why correct them, unless the aim is to make a - very public point?

In reality, the new regulations, which are published as a proposal open for public comment, do very little. Research institutions under the new regime will not only have to "commit themselves to implementing" animal care requirements - they will now have to "implement" them, a major crackdown if there ever was one. The only substantive change in the proposal is that the institutional animal care committees, charged with monitoring the use of laboratory animals at each research institution, would have to include one outside member.

NIH director James Wyngaarden set the tone for the NIH stance when, at last month's meeting, he declared his "deep concern" that public support for laboratory experiments involving animals may be eroding, the result of "politically sophisticated critics" who are attacking animal experiments as unnecessary and inhumane. NIH arguably have a role in public education to counter this trend, but need not sacrifice integrity in the process. If "political sophistication" means issuing meaningless regulations for the sake of appearances, NIH are better off with naivety. Or is it that by invoking the bogey of rabid antivivisectionists seeking to shut down biomedical research, $\mathrm{NIH}$ hope to distract attention from some serious proposals for reform (as opposed to revolution)?

It taxes credulity to claim that the extreme "animal rights" positions inherent in the antivivisectionists' stance are about to sway the overwhelmingly carnivorous population of the United States, or indeed that they are more than a sterile pseudophilosophical exercise. A much more serious threat to present practice is not the crazed antivivisectionists but, rather, some sensible criticisms from sensible people. Senator Robert Dole, for one, has introduced legislation that, while respecting the absolute freedom of researchers to design scientific protocols and to make their own judgements on the necessity of using animals, would clamp down on some of the more serious persisting abuses in the care of laboratory animals and their use. The bill would require the use of analgesics, tranquillizers and anaesthetics except when scientifically impossible, would forbid the use of the same animal in more than one major operative procedure and would require either proper postoperative care or prompt euthanasia. Enforcement would be left largely to the animal care committees, which would have to certify in regular reports that experimental procedures involving animals followed these requirements. Significantly, the bill does not limit the freedom of scientists to proceed with such experiments; it does, sensibly, require that investigators "consider" alternatives and consult with a veterinarian in planning procedures involving unanaesthetized animals.

There is hardly anything subversive about these proposals. (Nor is there anything subversive in demands of animal welfare activists, such as Mrs Christine Stevens of the Animal Welfare Institute, that inspections now required by federal law should actually be carried out to ensure that laboratory animal care meets the published guidelines - which means basic things like clean cages, proper food and proper ventilation.) The US Department of Agriculture, which is charged with carrying out the inspections, has never been given the funds to discharge its responsibilities under the law. Yet such inspections as it is able to carry out reveal continued problems in these basic necessities for humane care. NIH would do well to face up to these issues, rather than issuing pronouncements full of sound and fury that signify nothing. 